\begin{tabular}{|l|l|}
\hline Postprint Version & Final draft post-refereeing \\
\hline Journal website & $\underline{\text { http://www.sciencedirect.com/science/journal/09553959 }}$ \\
\hline Pubmed link & $\underline{\text { http://www.ncbi.nlm.nih.gov/pubmed/21705205 }}$ \\
\hline DOI & $\underline{10.1016 / \text { j.drugpo.2011.05.015 }}$ \\
\hline
\end{tabular}

\title{
A high proportion of users of low-threshold facilities with needle exchange programmes in Switzerland are currently on methadone treatment: implications for new approaches in harm reduction and care
}

Jean-Pierre Gervasoni, MD, MSc, Hugues Balthasar, MA, Thérèse Huissoud MA, André Jeannin MA, Françoise Dubois-Arber, MD, MSc, PH

Institute of Social and Preventive Medicine (IUMSP), University Hospital Center and University of Lausanne, Lausanne, Switzerland

\section{Corresponding author:}

Dr Jean-Pierre Gervasoni

Institute of Social and Preventive Medicine (IUMSP)

University Hospital Center

Bugnon 17

CH-1005 Lausanne

Tel.: +4121314 7294

Fax: +41213147373

Mail : Jean-Pierre.Gervasoni@chuv.ch

\section{ABSTRACT}

Background: Increasingly, patients receiving methadone treatment are found in Low Threshold Facilities (LTF), which provide needle exchange programmes in Switzerland. This paper identifies the characteristics of LTF attendees receiving methadone treatment (MT) compared with other LTF attendees (non-MT).

Methods: A national cross-sectional survey was conducted in 2006 over five consecutive days in all LTF $(n=25)$. All attendees were given an anonymous questionnaire, including information on socio-demographic indicators, drug consumption, injection, methadone treatment, and self-reported HIV and HCV status. Univariate analysis and logistic regression were performed to compare MT to non-MT. Response rate was 66\% ( $\mathrm{n}=1128)$.

Results: MT comprised $57.6 \%$ of the sample. In multivariate analysis, factors associated with being MT were older age (OR 1.38), female sex (OR: 1.60), having a 
own accommodation (OR: 1.56), receiving public assistance (OR: 2.29), lifetime injecting (OR: 2.26), HIV-positive status (OR: 2.00), and having consumed cocaine during the past month (OR: 1.37); MT were less likely to have consumed heroin in the past month (OR: 0.76, not significant) and visited LTF less often on a daily basis (OR: 0.59). The number of injections during the past week was not associated with MT.

Conclusions: More LTF attendees were in the MT group, bringing to light an underappreciated LTF clientele with specific needs. The MT group consumption profile may reflect therapeutic failure or deficits in treatment quality. It is necessary to acknowledge this reality and to strengthen the awareness of LTF personnel about potential needs of MT attendees to meet their therapeutic goals.

\section{Key words:}

Low-threshold facilities, methadone, needle exchange programmes, Switzerland, harm reduction

\section{INTRODUCTION}

In Switzerland, Low-Threshold Facilities (LTF) with needle exchange programmes are at the front line of the harm reduction policy(Kübler \& Wälti, 2001; Uchtenhagen, 1995; Zobel et al., 2003). They mostly provide sterile injection/inhalation equipment, basic health care, sometimes counselling, but no substitution treatments(Benninghoff, 1999). About half have a supervised drug consumption room (DCR) for injection or inhalation. LTF operate under the principle of anonymity, do not register clients; they may provide referrals but no follow-up.

Methadone is widely prescribed to heroin users, only in medical settings. Most treatments are long term maintenance, and persistence of some consumption is generally not considered a reason to exclude patients(Swiss Society of Addiction Medicine, 2010). About 2/3 of the 25,000 estimated heroin users are in treatment(Hosek, 2006; Maag, 2003; Schorr \& Künzi, 2007).

Previous studies, in Switzerland(Benninghoff, Morency, Geense, Huissoud, \& DuboisArber, 2006; Dubois-Arber et al., 2008) and elsewhere(Toufik, Cadet-Taïrou, Janssen, \& Gandilhon, 2008; Valenciano, Emmanuelli, \& Lert, 2001; E. Wood et al., 2005), have shown that a high proportion of LTF attendees - increasing in Switzerland - are currently on methadone treatment. Although this may not be surprising, it is not much recognized by LTF that do not have specific policies regarding these persons. Their characteristics are not well known, in particular, their consumption patterns and mode.

The aims of this paper are to analyse the extent to which LTF users on methadone treatment (MT) are different from other LTF users (non-MT) in terms of sociodemographic characteristics, drug use, health status, and social integration; and to discuss the implications of the findings for LTF management.

\section{METHODS}

A national cross-sectional survey among attendees of all LTF $(n=25)$ in Switzerland was conducted in 2006(Balthasar et al., 2007). This survey, included in the national HIV surveillance system since 1993, monitors consumption patterns and preventive 
behaviours in IDUs(Dubois-Arber, et al., 2008; Dubois-Arber, Jeannin, \& MeystreAgustoni, 2006).

During five consecutive days, all LTF attendees were invited to complete an anonymous questionnaire. The first part, related to consumption, was conducted face to face by trained interviewers; the second, including questions on health, was self-completed. The questionnaire included questions on:

- Age, sex, education, income (not mutually exclusive: from a paid job, social insurance, public assistance, illegal activity), own accommodation.

- Heroin and/or cocaine use in the past month, injection (never, ever and not previous week, previous week), and number of injections in previous week.

- Perceived health; HIV, HCV testing (ever) and self-reported results, current substitution treatment.

- Frequency of LTF visits (everyday, less often).

Number and characteristics of non-participants (sex, estimated age, reason for refusal) were documented.

The participation rate was $66.0 \%(n=1,128)$. Non-participants did not significantly differ from participants on sex and age. We excluded from the analysis the respondents:

- -who had never consumed heroin nor cocaine $(n=53)$;

- -who did not answer the question on injection $(\mathrm{n}=5)$;

- recruited from two LTF ( $\mathrm{n}=54)$, with on site delivery of methadone treatment by a physician;

To control potential bias, we also excluded respondents who had a substitution treatment other than methadone treatment $(n=95)$. The final sample size under analysis was 921 respondents.

Univariate analysis and logistic regression were performed to identify characteristics of patients in treatment (MT), versus non-treated (non-MT). Variables included were age in years and age squared, sex, heroin use (past month), cocaine use (past month), injection lifetime, number of injections (previous week), education, sources of income, own accommodation, perceived health status, self-reported HIV and HCV status, LTF attendance, recruitment in a LTF with an injection room (Table 1).

Missing data (less than 3.0\%), were excluded in the univariate analysis. The data were processed using SPSS software (version 15.0) for Windows (SPSS Inc., Chicago, Illinois 60606).

\section{RESULTS}

The average age of LTF attendees was 35.8 years. One fourth were women. $29.8 \%$ had completed only mandatory 9 years of schooling. $85.1 \%$ of participants lived in their own accommodation. 39.4\% had a job in the past month, $43.2 \%$ reported an income from public assistance, one third (33.1\%) from social insurance, and 21.2\% from illicit activities.

94.7\% had ever used heroin, $71.9 \%$ had used heroin and $62.6 \%$ cocaine in the past month. $78.0 \%$ had ever injected drugs, $47.1 \%$ in the past week. HIV and HCV prevalence (among tested) were respectively $7.3 \%$ and $49.3 \%$.

$57.6 \%$ of respondents were on methadone treatment. The average dosage was 72 $\mathrm{mg} /$ day (median, $60 \mathrm{mg} /$ day; range, 25 to $275 \mathrm{mg} /$ day). The average treatment duration was 6.2 years (median, 4.2 years; range, 1 to 288 months). 


\section{INSERT TABLE 1}

MT were more likely to be female and supported by social insurance or public assistance, and less likely to have a paid job. They reported living in their own accommodation more often and used LTF less regularly than non-MT.

MT were less likely to report heroin use in the past month $(67.2 \%$ vs. $78.4 \%, \mathrm{p}<0.001)$, but no significant difference was observed regarding cocaine use. Among non-MT, one third had never injected drugs in their lifetime compared with $14.6 \%$ among MT. Among those who had ever injected drugs in their lifetime, 57.0\% (non-MT) and 62.4\% (MT) had injected in the 7 last days (NS).

More MT reported to have been tested for HIV and HCV (data not shown) and the related reported prevalences were significantly higher among MT.

In logistic regression analysis (Table 1), the following variables were positively associated with the dependent variable (MT): older age, female sex, own accommodation in the past month, having a public assistance income, being HIVpositive, having ever injected, and having used cocaine during the past month. MT also tended to be less likely to have used heroin (not significant), and were less likely to visit the LTF daily. No association was found with the frequency of injection in previous week.

\section{DISCUSSION}

The profile of MT attendees corresponds with ageing drug users with a long history of injection. They may be considered persons for whom methadone treatment is not fully effective (doses too low to suppress consumption) and/or inadequate (medical follow-up of insufficient quality not allowing to identify the persistence of consumption and injection). Although the average dose of methadone reported by MT is in line with the current Swiss recommendations (60-80 mg)(Swiss Society of Addiction Medicine, 2010), the range is large. Regarding consumption, the profile of MT compared with non-MT is worrisome, having a higher proportion of cocaine users (probably replacing heroin in those who still need "shoots"), an absence of significant differences regarding the proportion of current heroine users, and no difference in the number of weekly injections. MT are also more likely to be HIV-positive. The picture emerging for MT in LTF is of a high risk population who would benefit from being identified as such and offered special attention to improve their treatment situation, including being offered supervised heroin treatment. Currently, this special attention is not offered in Switzerland and in some countries in Western Europe, who share the same LTF development(Hedrich, 2004).

Switzerland was one of the first countries to develop LTF in the urgent context of an HIV/AIDS epidemic and open drug scenes, in the nineties. The role of LTF, when methadone treatment was not well developed, was to attract marginalised drug users and to be the first contact they had with health services. This required low threshold access, strong harm reduction orientation, anonymity (no registration, no history taking), no treatment requirement, no follow up. This harm reduction orientation in LTF was successful(Benninghoff, et al., 2006). Over the same period, methadone treatment was developed in parallel. However, harm reduction and treatment domains remained somewhat separated conceptually, with different professional identifications and tracks (mostly medical in treatment centres, predominantly socio-educational in LTF). The situation has evolved, since, and the overlap between these two "worlds" is significant, although insufficiently acknowledged in Switzerland. Generally, in the articles cited 
above describing LTF clients(Toufik, et al., 2008; Valenciano, et al., 2001; E. Wood, et al., 2005), the high proportion of LTF users receiving methadone treatment is often mentioned, without further comment.

Various studies showed that participation in a needle exchange programme may have a positive impact on the identification of health and social problems and referral to treatment programmes(Committee on the prevention of HIV infection among injecting drug users in high-risk countries, 2006; Hagan et al., 2000; Henderson, Vlahov, Celentano, \& Strahtdee, 2003; Mac Master \& Vail, 2002; Riley, Safaeian, Strathdee, Beilenson, \& Vlahov, 2002). At population level, combination of LTF and adequate methadone treatment has been shown to contribute to decrease HIV and HCV transmission risk(van den Berg, Smit, van Brussel, Coutinho, \& Prins, 2007). In countries where development of LTF is more recent, the objective of referring drug users to treatment is more prominent(E. Wood, Tyndall, Montaner, \& Kerr, 2006). For example, in the context of the Vancouver DCR(E Wood et al., 2006), increased referral was noted when a social worker was actively working on this dimension. In Switzerland, however, LTF staff report not having enough time to discuss and orient drug users to other relevant health institutions(Spreyermann \& Willen, 2003).

Redefining the role and function of LTF for MT clients is needed. Their specific risks and needs should be better recognized. This implies reconsidering the issue of anonymity in LTF, and of the resources needed to be more proactive in identifying MT attendees and proposing a case management strategy in cooperation with treatment centres for those willing to do so. A specially trained professional (social worker, nurse) could initiate the collaboration with the medical doctor currently in charge of the treatment. Better identification of the treatment situation of LTF clients could improve treatment, including that of complex cases who often suffer from psychiatric problems. In the context of ageing cohorts of drug users, many of which receive long-term maintenance treatment, the sharp distinction between harm reduction centres and treatment centres should disappear.

This study has limitations; non-respondents may differ from respondents on variables related to treatment or drug consumption; the methadone dose is the only proxy for treatment quality, and there was no specific assessment of mental condition that may be a confounder for (failed) treatment.

\section{ACKNOWLEDGMENTS}

The study was funded by the Federal Office of Public Health, Berne, Switzerland. Contract number 04.000158 / 2.24.01-744.

\section{CONFLICTS OF INTEREST STATEMENT}

The authors declare that there are no conflicts of interest. 
Table 1 Variables associated with being on methadone treatment (MT)

\begin{tabular}{|c|c|c|c|c|c|c|c|c|c|c|c|c|}
\hline & Factors & $\begin{array}{c}\mathrm{n} \\
\mathrm{MT} \\
\end{array}$ & $\begin{array}{c}\text { non- } \\
\text { MT }\end{array}$ & $\%$ & $\begin{array}{l}\text { ivariate } \\
\text { ociation } \\
=921)^{*} \\
\text { OR }\end{array}$ & $\begin{array}{c}95 \% \\
\text { IC } \\
\end{array}$ & & $p=$ & OR & $\begin{array}{c}\text { Multivariate } \\
\text { logistic } \\
\text { regression } \\
(\mathrm{n}=843)^{\star *} \\
95 \% \text { IC } \\
\end{array}$ & & $p=$ \\
\hline \multirow[t]{2}{*}{ Sex } & Male & 374 & 309 & 54.8 & 1.00 & & & & 1.00 & & & \\
\hline & Female & 151 & 77 & 66.2 & 1.62 & 1.18 & ; 2.21 & 0.01 & 1.60 & 1.10 & ; 2.32 & 0.01 \\
\hline Age & & & & & 1.42 & 1.25 & ; 1.62 & $<0.01$ & 1.38 & 1.19 & ; 1.61 & $<0.01$ \\
\hline Age (squared) & & & & & 0.99 & 0.99 & ; 1.00 & $<0.01$ & 1.00 & 0.99 & ; 1.00 & $<0.01$ \\
\hline \multirow[t]{2}{*}{ Education } & Mandatory school & 149 & 121 & 55.2 & 1.00 & & & & 1.00 & & & \\
\hline & Any higher degree & 376 & 261 & 59.0 & 1.17 & 0.88 & ; 1.56 & 0.28 & 1.18 & 0.83 & ; 1.68 & 0.37 \\
\hline \multicolumn{13}{|l|}{ Income } \\
\hline \multirow[t]{2}{*}{ Paid job } & No & 342 & 216 & 61.3 & 1.00 & & & & 1.00 & & & \\
\hline & Yes & 191 & 172 & 52.6 & 0.7 & 0.54 & ; 0.91 & 0.01 & 0.77 & 0.54 & ; 1.11 & 0.16 \\
\hline \multirow[t]{2}{*}{ Social insurance } & No & 346 & 270 & 56.2 & 1.00 & & & & 1.00 & & & \\
\hline & Yes & 187 & 118 & 61.3 & 1.24 & 0.93 & ; 1.64 & 0.14 & 1.12 & 0.75 & ; 1.66 & 0.54 \\
\hline \multirow[t]{2}{*}{ Public assistance } & No & 272 & 251 & 52.0 & 1.00 & & & & 1.00 & & & \\
\hline & Yes & 261 & 137 & 65.6 & 1.76 & 1.34 & ; 2.31 & $<0.01$ & 2.29 & 1.57 & ; 3.32 & $<0.01$ \\
\hline \multirow[t]{2}{*}{ Illegal activity } & No & 436 & 290 & 60.1 & 1.00 & & & & 1.00 & & & \\
\hline & Yes & 97 & 98 & 49.7 & 0.66 & 0.48 & ; 0.91 & 0.01 & 0.72 & 0.49 & ; 1.06 & 0.09 \\
\hline \multirow[t]{2}{*}{ Own accommodation (past month) } & No & 69 & 68 & 50.4 & 1.00 & & & & 1.00 & & & \\
\hline & Yes & 464 & 320 & 59.2 & 1.43 & 0.99 & ; 2.06 & 0.05 & 1.56 & 1.00 & ; 2.44 & 0.05 \\
\hline \multirow[t]{2}{*}{ Perceived health status } & Good, rather good & 369 & 270 & 57.7 & 1.00 & & & & 1.00 & & & \\
\hline & Bad, rather bad & 144 & 93 & 60.8 & 1.13 & 0.84 & ; 1.54 & 0.42 & 1.14 & 0.81 & ; 1.62 & 0.75 \\
\hline \multirow[t]{2}{*}{ Injection lifetime } & No & 78 & 125 & 38.4 & 1.00 & & & & 1.00 & & & \\
\hline & Yes & 455 & 263 & 63.4 & 2.77 & 2.00 & ; 3.85 & $<0.01$ & 2.26 & 1.52 & ; 3.36 & $<0.01$ \\
\hline
\end{tabular}




\begin{tabular}{|c|c|c|c|c|c|c|c|c|c|c|c|c|}
\hline Number of injections last week & & & & & 1.02 & 0.99 & ; 1.04 & 0.11 & 0.99 & 0.98 & 1.00 & 0.07 \\
\hline \multirow[t]{2}{*}{ Heroin use (past month) } & No & 173 & 83 & 67.6 & 1.00 & & & & 1.00 & & & \\
\hline & Yes & 355 & 301 & 54.1 & 0.57 & 0.42 & ; 0.77 & $<0.01$ & 0.76 & 0.53 & 1.08 & 0.13 \\
\hline \multirow[t]{2}{*}{ Cocain use (past month) } & No & 187 & 154 & 54.8 & 1.00 & & & & 1.00 & & & \\
\hline & Yes & 340 & 231 & 59.5 & 1.21 & 0.92 & ; 1.59 & 0.16 & 1.37 & 1.00 & 1.89 & 0.05 \\
\hline \multirow[t]{2}{*}{ HIV status (reported) } & Seronegative & 481 & 373 & 56.3 & 1.00 & & & & 1.00 & & & \\
\hline & Seropositive & 52 & 15 & 77.6 & 2.69 & 1.48 & ; 4.87 & $<0.01$ & 2.00 & 1.02 & 3.91 & 0.04 \\
\hline \multirow[t]{2}{*}{ HCV status (reported) } & Seronegative & 290 & 272 & 51.6 & 1.00 & & & & 1.00 & & & \\
\hline & Seropositive & 243 & 116 & 67.7 & 1.96 & 1.49 & ; 2.60 & $<0.01$ & 1.13 & 0.80 & 1.61 & 0.49 \\
\hline \multirow{2}{*}{$\begin{array}{l}\text { Recruited in LTF with } \\
\text { injection room }\end{array}$} & No & 151 & 119 & 55.9 & 1.00 & & & & 1.00 & & & \\
\hline & Yes & 382 & 269 & 58.7 & 1.12 & 0.84 & ; 1.49 & 0.44 & 1.24 & 0.88 & 1.76 & 0.22 \\
\hline \multirow[t]{2}{*}{ Frequency of LTF visit } & less than everyday & 385 & 230 & 62.6 & 1.00 & & & & 1.00 & & & \\
\hline & everyday & 141 & 155 & 47.6 & 0.54 & 0.41 & ; 0.72 & $<0.01$ & 0.59 & 0.42 & 0.84 & $<0.01$ \\
\hline
\end{tabular}

* Number of participants may differ in univariate analysis due to excluded missing data

** Participants with full information were included in the multivariate logistic regression 


\section{REFERENCES}

Balthasar, H., Huissoud, T., Zobel, F., Arnaud, S., Samitca, S., Jeannin, A., . . . Dubois-Arber, F. (2007). Evolution de la consommation et des pratiques à risques de transmission du VIH et du VHC chez les consommateurs de drogue par injection en Suisse, 19932006. Bulletin de l'Office Fédéral de la Santé Publique, 45, 804-809.

Benninghoff, F. (1999). Prise en charge de la toxicodépendance en Suisse: une typologie des offres d'aide à 'bas seuil' et à 'haut seuil'. In C. Maeder, C. Burton-Jeangros \& M. Haour-Knipe (Eds.), Santé, médecine et société: contributions à la sociologie de la santé (pp. 315-331). Zurich: Seismo Verlag.

Benninghoff, F., Morency, P., Geense, R., Huissoud, T., \& Dubois-Arber, F. (2006). Health trends among drug users attending needle exchange programmes in Switzerland (1994-2000). Aids Care-Psychological and Socio-Medical Aspects of Aids/Hiv, 18(4), 371-375.

Committee on the prevention of HIV infection among injecting drug users in high-risk countries. (2006). Preventing HIV infection among injecting drug users in high-risk countries. An assessment of the evidence: The National Academies Press.

Dubois-Arber, F., Balthasar, H., Huissoud, T., Zobel, F., Arnaud, S., Samitca, S., . . . Gervasoni, J.-P. (2008). Trends in drug consumption and risk of transmission of HIV and hepatitis C virus among injecting drug users in Switzerland, 1993-2006. Euro Surveill., 13(21), 1-6.

Dubois-Arber, F., Jeannin, A., \& Meystre-Agustoni, G. (2006). Un système de surveillance de deuxième génération pour améliorer la surveillance du VIH/sida en Suisse. Bulletin de l'Office Fédéral de la Santé Publique, 15, 277-281.

Hagan, H., McGough, J. P., Thiede, H., Hopkins, S., Duchin, J., \& Alexander, E. R. (2000). Reduced injection frequency and increased entry and retention in drug treatment associated with needle exchange participation in Seattle drug injectors. Journal of Substance Abuse Treatment, 19(3), 247-252.

Hedrich, D. (2004). European report on drug consumption rooms. Lisbonne: European Monitoring Centre for Drugs and Drug Addiction (EMCDDA).

Henderson, L. A., Vlahov, D., Celentano, D. D., \& Strahtdee, S. A. (2003). Readiness for cessation of drug use among recent attenders and nonattenders of a needle exchange program. Journal of Acquired Immune Deficiency Syndromes, 32(2), 229-237.

Hosek, M. (2006). Substitutionsbehandlungen in der Schweiz: Fortsetzung einer Erfolgsgeschichte. Suchtmagazin(1), 3-9.

Kübler, D., \& Wälti, S. (2001). Drug policy-making in metropolitan areas: urban conflicts and governance. International journal of urban and regional research, 25(1), 35-54.

Maag, V. (2003). Estimated trends in the prevalence of heroin addiction in Switzerland: A multiple-indicator approach. European Addiction Research, 9, 176-181.

Mac Master, S. A., \& Vail, K. A. (2002). Demystifying the injection drug user: willingness to participate in traditional drug treatment services among participants in a needle exchange program. Journal of Psychoactive Drugs, 34(3), 289-294.

Riley, E. D., Safaeian, M., Strathdee, S. A., Beilenson, P., \& Vlahov, D. (2002). Drug treatment referrals and entry among participants of a needle exchange program. Substance Use and Misuse, 37(14), 1869-1886.

Schorr, D., \& Künzi, U. (2007). Was sagt uns die methadonstatistik über die Entwicklung der letzten Jahre? Ein Vergleich zwischen ausgewählten Kantonen [What do the 
methadone statistics tell us about developments over the last few years?]. Abhängigkeiten(3).

Spreyermann, C., \& Willen, C. (2003). Analyse der Tätigkeiten und Angebotsbereiche in Anlaufstellen. Bern: Sfinx.

Swiss Society of Addiction Medicine. (2010). Substitution-assisted treatment in opioid dependence. Summary of the clinical recommendations for Substitution-assisted treatment (SAT) in opioid dependence issued by the SSAM (Swiss Society of Addiction Medicine) in 2007. Bern: Federal Office of Public Health.

Toufik, A., Cadet-Taïrou, A., Janssen, E., \& Gandilhon, M. (2008). Première enquête nationale sur les usagers des CAARUD. Tendances, 61, 1-4.

Uchtenhagen, A. (1995). Harm reduction: the case of Switzerland. European Addiction Research, 1, 86-91.

Valenciano, M., Emmanuelli, J., \& Lert, F. (2001). Unsafe injecting practices among attendees of syringe exchange programmes in France. Addiction, 96(4), 597-606.

van den Berg, C. H., Smit, C., van Brussel, G., Coutinho, R., \& Prins, M. (2007). Full participation in harm reduction programmes is associated with decreased risk for human immunodeficiency virus and hepatitis $C$ virus: evidence from the Amsterdam Cohort Studies among drug users. Addiction, 102(9), 1454-1462.

Wood, E., Tyndall, M., Qui, Z., Zhang, R., Montaner, J., \& Kerr, T. (2006). Service uptake and characteristics of injection drug users utilizing North America's first medically supervised safer injection facility. American Journal of Public Health, 96(5), 770-773.

Wood, E., Tyndall, M. W., Li, K., Lloyd-Smith, E., Small, W., Montaner, J. S., \& Kerr, T. (2005). Do supervised injecting facilities attract higher-risk injection drug users? American Journal of Preventive Medicine, 29(2), 126-130. doi: 10.1016/j.amepre.2005.04.011

Wood, E., Tyndall, M. W., Montaner, J. S., \& Kerr, T. (2006). Summary of findings from the evaluation of a pilot medically supervised safer injecting facility. CMAJ: Canadian Medical Association Journal = Journal de l'Association Médicale Canadienne, 175(11), 1399-1404. doi: 10.1503/cmaj.060863

Zobel, F., Thomas, R., Arnaud, S., De Preux, E., Ramstein, T., Spencer, B., et al. (2003). Evaluation of the Confederation's measures to reduce drug-related problems: Fourth synthesis report 1999-2002. Lausanne: Institut universitaire de médecine sociale et préventive. 